\title{
'||||||||||||||||||||||||||||||||||||||||||||||||||||||||||||||||||.
}

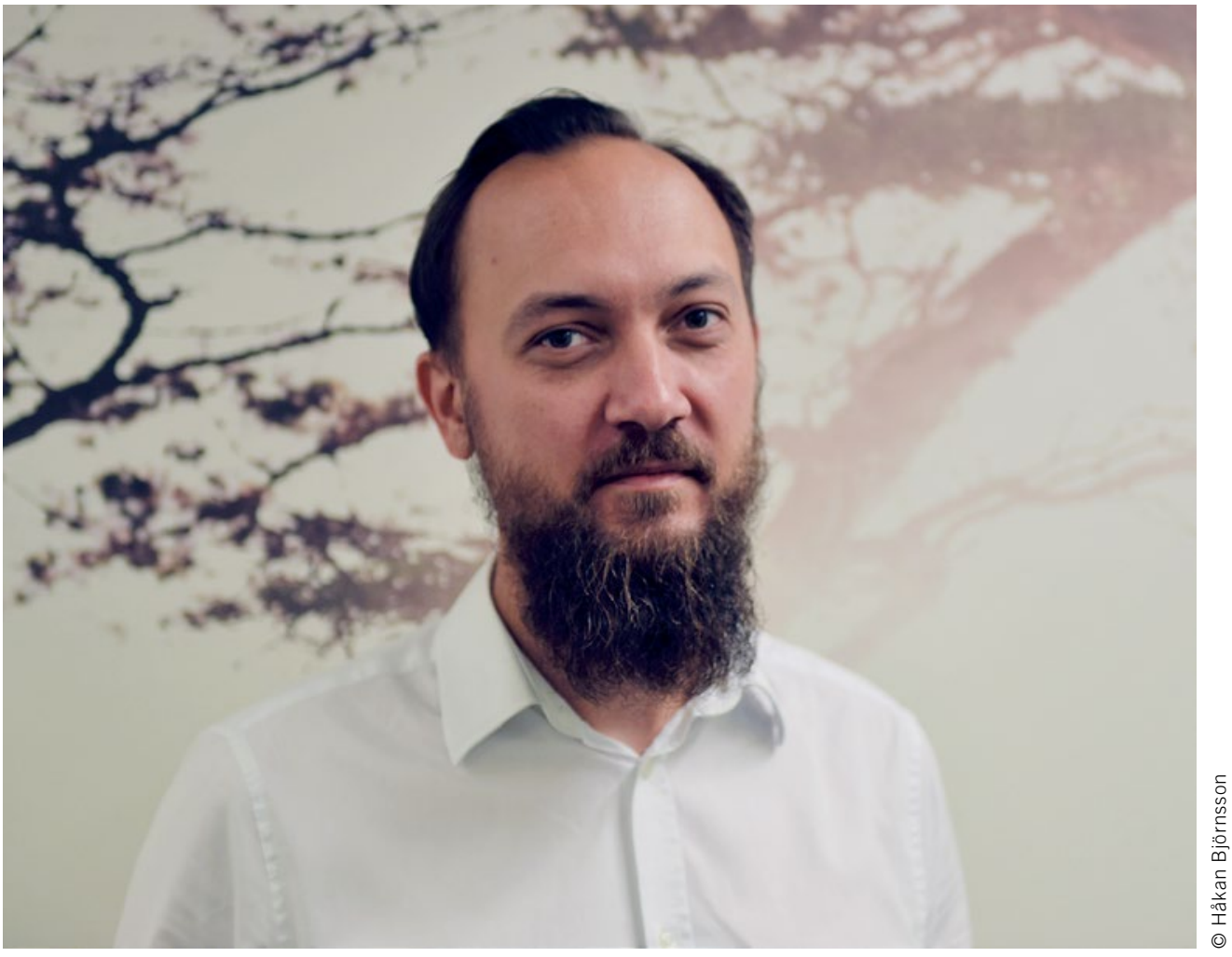

Ragnar Burenius

Chief Program Engineer for Internal Combustion Engines of Volvo in Gothenburg (Sweden)

\section{New Requirements in a Different Normal}

I think I speak for most of us when I say that so far 2020 has been a different year indeed. Us fortunate ones that have been lucky enough to avoid infection have anyway had our lives changed by the necessary restrictions to limit the spread of the coronavirus. Hopefully we are well on our way back to normality, but it might be to a different normal compared to when the year began. For us as an industry the impact has not only been the obvious and unavoidable decrease in sales, but also a change to how we conduct our daily operation. It is no longer given that you meet your colleagues for a chat at the water cooler or by the coffee machine, and our interactions with fellow suppliers and customers are through filters of Skype, Teams and Zoom.

These are changes affecting an industry that already was in transformation. Even with combustion-engine-based powertrains being the overall dominant source of power for the years to come; the wider offer of electrified products will impact the customers' expectations. Those buyers for which a fully electric car isn't the suitable choice will most likely anyway have driven or experienced an electric powertrain. With that comes adjusted references. Modern electric cars excel in transient response and drivability around town, and why should I expect anything less from my luxury, combustion powered, SUV?
Additionally, a large part of the sales growth of recent years has been in younger markets where it isn't given that the soft rumble of a combustion engine car of the past is part of your childhood memories. Why should my car make a noise when it starts, and why does it vibrate? A wider offer of electric cars might for traditional powertrains mean an equally strong impact in terms of shifted customer expectations as it has in terms of sales numbers.

Personally, I believe the hybrid powertrain will play an even more important role in the future. It allows us to offer the electrical drives positive attributes of a swift, silent, take-off, while further improving on the combustion powertrains' strengths of infrastructure independence and versatility for long range travel at speed. However, maintaining the mass market price point will require highly efficient and integrated solutions. Engines and hybrid transmission systems need to be developed in concert and be designed for global production systems allowing for economy of scale. This means the need for close collaborations, both across teams, across organizations and across the globe. Communication and relations with colleagues and suppliers will for us as an industry be more important than ever, even in a slightly different normal. 